\title{
Ang Hermenyutika nina Schleiermacher at Dilthey bilang Batayang Teoretikal sa Araling Pilipino
}

\section{F.P.A. Demeterio}

\begin{abstract}
This paper is a reconstruction of the hermeneutical theories of Friedrich Schleirmacher and Wilhem Dilthey and an initial attempt to contextualize their ideas within the framework of Philippine Studies. In particular, the paper explores the use of the hermeneutical method in reading local texts and culture.
\end{abstract}

Key words: Schleiermacher, Dilthey, hermeneutics, Philippine Studies

\section{Ang Konsepto ng Hermenyutika} \begin{abstract}
A

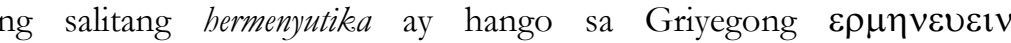
(hermeneuein), na ang ibig sabihin ay "gagawa ng interpretasyon," at $\varepsilon \rho \mu \eta v \varepsilon 1 \alpha$ (hermeneia), na ang ibig sabihin naman ay "proseso ng interpretasyon." Mayroon itong linguistikong ugnayan sa pangalan ni Hermes, ang maliksing mensahero ng mga diyos sa Bundok Olympus, na dapat bihasang-bihasa sa kanilang wika at sa wika ng mga tao para matagumpay niyang maipaparating ang mga saloobin sa magkabilaang panig ng mga mortal at imortal.
\end{abstract}

Ang pinakapayak na kahulugan ng hermenyutika ay: isang teorya, metodolohiya at proseso ng interpretasyon na nakatuon sa pagtukoy sa kahulugan ng isang teksto, o anumang bagay na mala-teksto, na nagmumula sa ibang panahon o kultura, o hindi kaya nababalutan ng ideolohiya at maling kamalayan. May presuposisyon ang hermeneyutika na para sa isang indibidwal ang anumang bagay na nagmumula sa ibang panahon at kultura, o hindi kaya nababalutan ng ideolohiya at maling kamalayan, ay magmimistulang magulo, hindi kumpleto, napupuno ng kontradiksyon at distorsyon, at nangangailangan ng isang sistematikong proseso ng interpretasyon para matunghayan ang kanyang nakakubling kahulugan.

Naghahayag ang payak na kahulugang ito na may tatlong antas ang hermenyutika: 1) teorya, na nakatuon sa epistemolohikal at sikolohikal na usapin ng interpretasyon; 2) pamamaraan, na nakatuon sa pagbuo ng maaasahang sistema ng interpretasyon; at 3) ang aktwal na proseso ng interpretasyon na nakatuon naman sa praktikal na pagbabasa at pagsusuri ng partikular na mga teksto. Ngunit sa kabanatang ito, at sa mga susunod na 


\section{SCHLEIERMACHER AT DILTHEY}

kabanatang may kinalaman sa kaparehong paksa, tututok lamang tayo sa hermenyutika bilang pamamaraan sa pag-asang hinahanda natin ang mga mambabasa na magsagawa ng kani-kanilang proyektong may kinalaman sa interpretasyon.

\section{Hermenyutika ayon kay Schleiermacher}

Si Friedrich Schleiermacher (1768-1834), bilang isang Protestanteng dalubhasa sa teolohiya, bibliya, pilolohiya at edukasyon, ay may mahabang karanasan sa aktwal na proseso ng interpretasyon ng mga teksto sa wikang Hebreo, Griyego at Latin. Batid niya ang pagmimistulang magulo, hindi kumpleto, at pagkakaroon ng kontradiksyon at distorsyon ng ganitong mga teksto; at naisip niya na ang pangunahing dahilan ng mga problemang ito ay ang pagkawalay ng mga tekstong ito sa kani-kanilang orihinal na lingguwistika at sikolohikal na mga konteksto. Para sa ating mga Pilipino, halimbawa, ang isang nobelang Hapones, kahit pa man ito ay naisalin na sa wikang Filipino o sa Ingles, ay mahirap intindihin dahil hindi natin alam ang mga kumbensyon at pasikot-sikot ng wikang Nihonggo bilang midyum ng komunikasyon at panitikan. Pati ang isang Hapones, kahit pa man batid niyang lubos ang parehong wika, ay mahihirapan pa rin kapag hindi niya nalalaman ang pananaw at sikolohiya ng may-akda ng nasabing nobela. Naniniwala si Schleiermacher na may ugnayan ang mga teksto, hayagan man o hindi, sa kani-kanilang orihinal na lingguwistika at sikolohikal na konteksto, at kapag napapatid ang ugnayang ito lumalabo ang kahulugan ng teksto sa pananaw ng isang mambabasa.

Buo ang paniniwala ni Schleiermacher na possibleng mabubuo muli ang kahulugan ng isang teksto sa pamamagitan ng isang sistematikong pamamaraan ng interpretasyon. Paulit-ulit niyang sinabi na ang proseso ng interpretasyon ay nakatuon dapat sa pag-uunawa ng teksto na mas mahusay pa kaysa pag-kakaunawa nito ng sariling may-akda. Kahit pa man nagmumukhang eksaherado ang kanyang binibitiwang salita, nakabatay ito sa isang pulido at lohikal na pangangatuwiran. Para kay Schleiermacher sa pagkakataong nagsusulat ng teksto ang isang may-akda sumusunod ito sa mga pamantayan at kumbensyon ng kanyang wika, panahon, at kultura, mga pamantayan at kumbensyong malay, hindi lubusang malay, at hindi malay (tingnan ang Pigura 1).

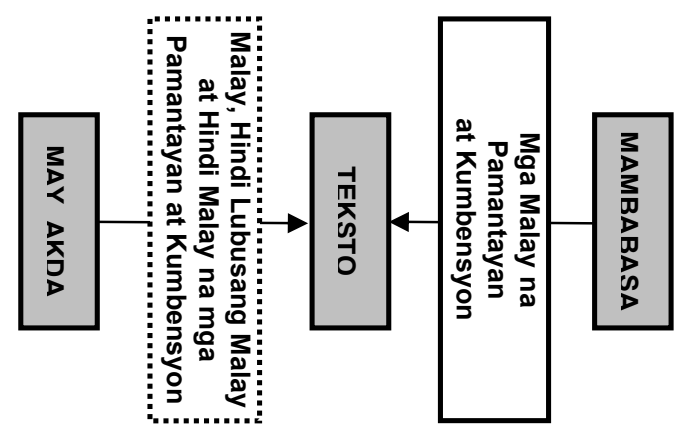

Pigura 1: Pag-uunawa ng May-akda at ng Sistematikong Mambabasa at ang mga Pamantayan at Kumbensyon na Batid, Hindi Lubusang Batid at Hindi Nila Batid 
Ang mambabasa na nagmumula sa ibang wika, panahon at kultura, ay kailangang maging bihasa muna hindi lamang sa sa mga malay na pamantayan at kumbensyong ginamit ng may-akda, kung hindi pati na rin sa mga hindi lubusang malay at hindi malay na pamantayan at kumbensyon. Kaya sa pagkakataong uumpisahan na ng mambabasa ang aktwal na proseso ng interpretasyon, lumalabas na may bentahe siya kumpara sa may-akda dahil batid niya ang mga pamantayan at kumbensyon ng wika, panahon at kultura ng mayakda (tingnan ang hugis 1). Kaya hindi eksaherado ang minimithi ni Schleiermacher na sa pamamagitan ng hermenyutika matatamo ng mambabasa ang pagkakaunawa na mas mahusay pa kaysa pagkakaunawa ng sariling mayakda ng anumang teksto.

Para kay Schleiermacher ang kahulugan ng isang teksto ay ang kahulugan na nasa isip ng may-akda noong isunulat niya ito. Ipinaliwanag ni Hans-Georg Gadamer, isang batikang teorisista ng hermenyutika, na: "ang dapat mauunawaan (ng mambabasa) ay hindi lamang ang mga eksaktong salita at ang kanilang obhektibong kahulugan, kung hindi pati na rin ang indibidwalidad ng nagsasalita o ng may-akda. Naniniwala si Schleiermacher na ang may-akda ay lubusang mauunawaan lamang sa pamamagitan ng pagbabalik doon sa pinagmumulan ng kaisipan."1 Para matukoy muli ang kahulugang ito nagmungkahi si Schleiermacher ng dalawang proseso ng rekonstraksyon: ang gramatikal at sikolohikal na rekonstraksyon. Sinabi niya: "bago maisasagawa ang sining ng hermenyutika, ang mambabasa ay dapat obhektibo at subhektibong pumunta sa katayuan ng may-akda. Sa obhektibong panig, dapat niyang malalaman ang wika ayon sa pagkakaalam nito ng may-akda. . . Sa subhektibong panig, dapat niyang malalaman ang panloob at panlabas na mga aspeto ng buhay ng may-akda."2

Ang proseso ng gramatikal na rekonstraksyon ay tungkol sa pagbubuo muli sa lingguwistikang konteksto ng sinusuring teksto (tingnan ang hugis 2). Nangunguna dito ang pag-aaral ng mambabasa sa wika na ginagamit ng mayakda. Bilang isang batikang tagasalin, alam ni Schleiermacher na isang pagtatantya lamang ang salin sa kahulugan ng orihinal na tektso, kaya dapat lamang na ang pagtutuonan ng pansin ng anumang interpretasyon ay ang orihinal na teksto mismo. Kaya kapag libro ni Platon ang sinusuri dapat alam ng mambabasa ang partikular na Griyego na ginagamit doon sa Atena noong panahon ni Platon. Pumapangawala dito ang pag-aalam ng genre ng teksto, dahil dapat lamang na babasahin ang isang trahedya, halimbawa, bilang trahedya at hindi bilang komedya, o ang kwentong bayan bilang kwentong bayan at hindi bilang kasaysayan. Pumapangatlo, dapat ding marekonstrak ng mambabasa ang kabuuang obra ng may-akda sa pamamagitan ng pag-aaral ng ibang teksto na gawa ng may-akda, kahit pa man ang mga ito ay nasa ibang genre. Halimbawa, para lubusan nating maintindihan ang unang nobela ni Jose Rizal, malaking

\footnotetext{
${ }^{1}$ Hans-Georg Gadamer, Truth and Method (New York: Continuum Publishing Company, 1999), 186.

${ }^{2}$ Friedrich Schleiermacher, "General Hermeneutics," in Mueller-Vollmer, Kurt, Ed., The Hermeneutics Reader (New York: Continuum Publishing Company, 1997), 83-84.
} 


\section{SCHLEIERMACHER AT DILTHEY}

tulong ang maidudulot ng pag-aaral natin sa kanyang mga naisulat na tula, liham, sanaysay at iba pa. Pumapang-apat, dapat ding marekonstrak ng mambabasa ang katawan ng mga obra na gawa ng mga taong kakontemporaryo ng may-akda. Kapag ang unang nobela ulit ni Rizal ang ating gagamiting halimbawa, mahalagang babasahin din natin ang mga tekstong isinulat ng kanyang mga kaibigan, kasamahan, at kapwa Pilipinong sangkot sa pakikibaka laban sa mga mananakop na Espanyol, tulad nina Pedro Paterno, Isabelo delos Reyes, Marcelo del Pilar, Andres Bonifacio, at iba pa.

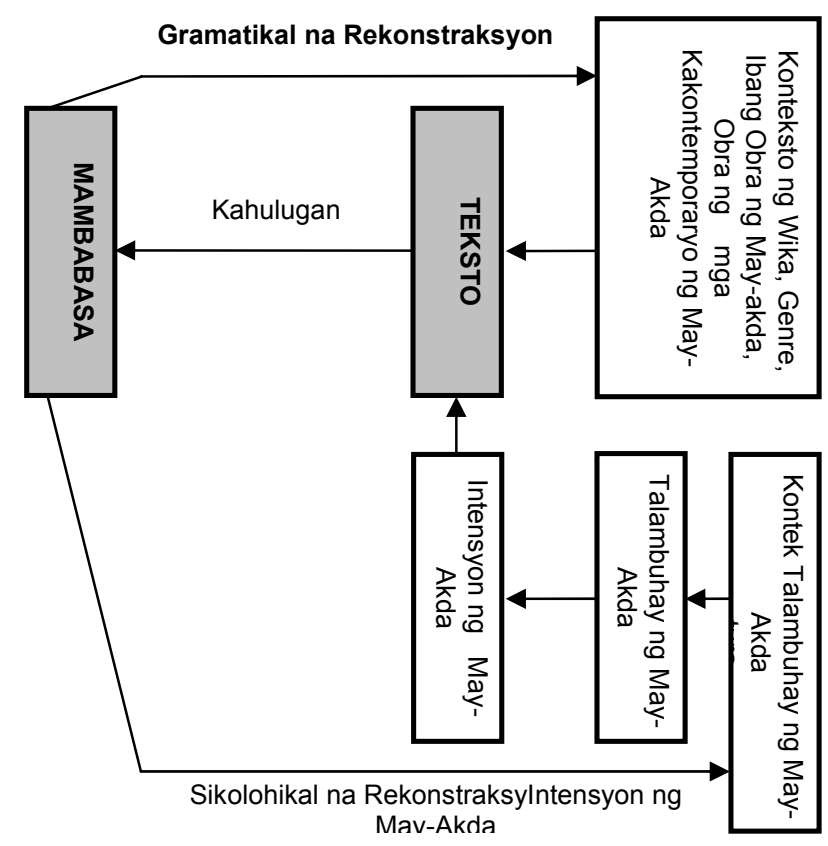

Pigura 2: Ang Gramatikal at Sikolohikal Rekonstraksyon bilang mga Proseso sa Pagtukoy ng Kahulugan ng Teksto

Nakatuon naman ang sikolohikal na rekonstraksyon sa pagbubuo muli ng sikolohikal na konteksto ng sinusuring teksto, o ang sikolohiya ng may-akda (tingnan ang hugis 2). Binanggit na ni Schleiermacher na dapat malaman ng mambabasa "ang panloob at panlabas na mga aspeto ng buhay ng may-akda." Ang panloob na aspeto ay ang talambuhay ng may-akda. Kapag gusto nating maintindihan nang lubusan ang mga kwento ni Nick Joaquin, halimbawa, mahalagang tingnan natin muli ang naging buhay ng manunulat na ito. Ang panlabas na aspeto sa buhay ng may-akda naman ay sumasaklaw sa kanyang kinabibilangang historikal at kultural na konteksto. Kapag si F. Sionil Jose ang paguusapan natin, lalong titingkad ang mensahe ng kanyang mga nobela kapag alam natin ang historikal at kultural na mga usaping bumagabag at humuhugis sa kanyang kamalayan, tulad ng problemang agraryan, Pangalawang Digmaan, Batas Militar, malawakang kahirapan, at iba pa. Ang historikal at kultural na 
mga konteksto ang silang humuhugis sa sikolohiya ng may-akda, na siya namang nagbibigay hugis sa tekstong sinusuri.

Ang salitang Romantisismo ay tumutukoy sa isang pampanitikan, pangsining at kultural na kilusan sa Europa noong ika-18 at ika-19 na daangtaon na kumakalaban sa mga pagpapahalaga ng Enlightenment, partikular na sa empirisismo ng agham at sa dedaktibong rasyonalidad ng pilosopiya. Bilang pagkontra sa kamalayang pinapalaganap ng Enligtenment, inilahad ng Romantisismo ang kapangyarihan ng intuwisyon, imahinasyon, at damdamin. Sa puntong ito hindi pa natin makikita ang pagiging Romantisista ni Schleiermacher dahil litaw na litaw pa ang pagkalohikal, pagkasistematiko at pagkasiyantipiko ng kanyang hermenyutikal na pamamaraan. Sa katunayan, napakamabisa ang programang iminungkahi niya sa antas ng aktwal na interpretasyon, sa puntong binago nito ang landas ng pag-inog ng biblikal at historikal na pananaliksik.

Ngunit sa antas ng hermenyutika bilang teorya at epistemolohiya, natuklasan ni Schleiermacher ang isang malalim na suliraning taglay ng kanyang dalawang kontekstwal na rekonstraksyon. Ipinahayag niya na: "ang wika ay walang hangganan dahil bawat elemento nito ay naaapektuhan sa espesyal na paraan ng ibang elemento. Ito ay ganoon din sa sikolohikal na interpretasyon, dahil ang bawat intuwisyon ng isang tao ay walang hangganan. Dagdag pa dito, ang mga panlabas na impluwensya sa isang tao ay maaaring magsasanga-sanga papuntang walang hangganan.”3 Dahil hindi malinaw para sa isang mambabasa kung saan siya dapat titigil sa kanyang pagiging bihasa sa wika, genre, ibang obra ng mayakda, at ibang obra ng mga taong kakontemporaryo ng may-akda, hindi rin malinaw para sa kanya kung talaga bang narerekonstrak na niya ang lingguwistikang konteksto ng tekstong sinusuri niya (tingnan ang hugis 3). Kapag hindi malinaw ang kontekstong ito, hindi rin malinaw kung matutukoy niya ba talaga ang kahulugan ng tekstong ito.

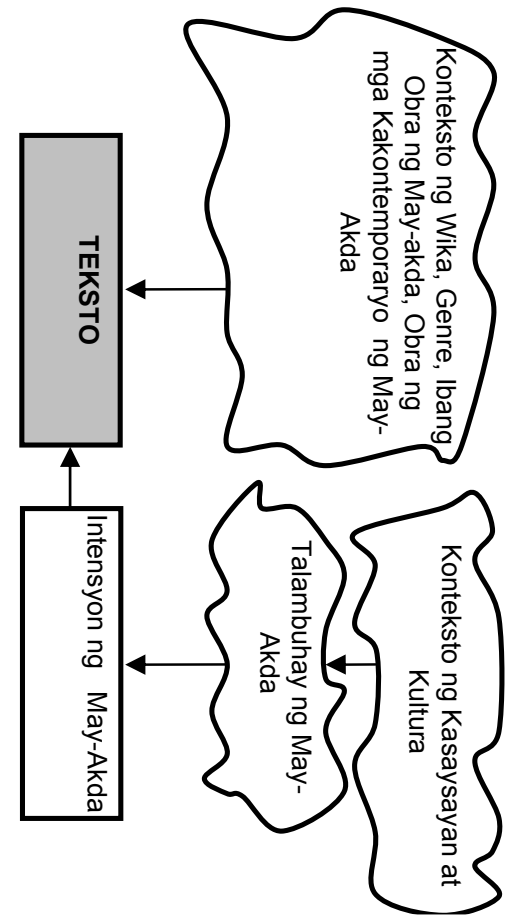

Pigura 3: Ang mga Hindi Malilinaw na Hangganan ng Kontekstong Lingguwistika, Pantalambuhay, Historikal at Kultural

Gayundin, dahil hindi malinaw para sa isang mambabasa kung saan siya dapat titigil sa kanyang pag-aaral sa historikal, kultural at pantalambuhay na konteksto ng may-akda, hindi rin malinaw para sa kanya kung talaga bang narerekonstrak na niya ang sikolohikal na konteksto ng tekstong sinusuri niya 


\section{SCHLEIERMACHER AT DILTHEY}

(tingnan ang hugis 3). Kapag hindi malinaw ang kontekstong ito, hindi rin malinaw kung matutukoy niya ba talaga ang kahulugan ng tekstong ito.

Ang teoretikal na suliranin na ito ay sumira sa dating akala ni Schleiermacher na matatag na pundasyon ng kahulugan at kalaunan ay nagtulak sa kanyang aminin na ang teksto ay maaaring mayroong hindi mabibilang na kahulugan, kumporme kung hanggang saan tumitigil ang mambabasa sa kanyang pagrerekonstrak ng lingguwistika at sikolohikal na mga konteksto nito. Dagdag pa dito inamin din niya na kahit lubus-lubusin pa ng mambabasa ang pagrekonstrak ng lingguwistika at sikolohikal na mga konteksto hindi pa rin niya masisigurado kung talaga bang matagumpay na niyang napasok ang kaisipan ng may-akda. Sa kabila ng pagkakaroon ng teksto ng maraming potensyal na kahulugan, at sa kabila ng agam-agam na bumabagabag sa kahit pinakamisinop na mambabasa, kumbinsido pa rin si Schleiermacher na ang pinakasukatan ng kahulugan ay ang kahulugang taglay sa isipan ng may-akda noong isinulat niya ang tekstong sinusuri. Kaya para matukoy ang intensyonal na kahulugang ito nagmungkahi siya ng isa pang proseso: ang divinatory na rekonstraksyon (tingnan ang hugis 4). Sa prosesong ito sisikapin ng mambabasa ang isang agarang pag-uunawa ng teksto sa pamamagitan ng pagsasabuhay ng sikolohiya ng may-akda.

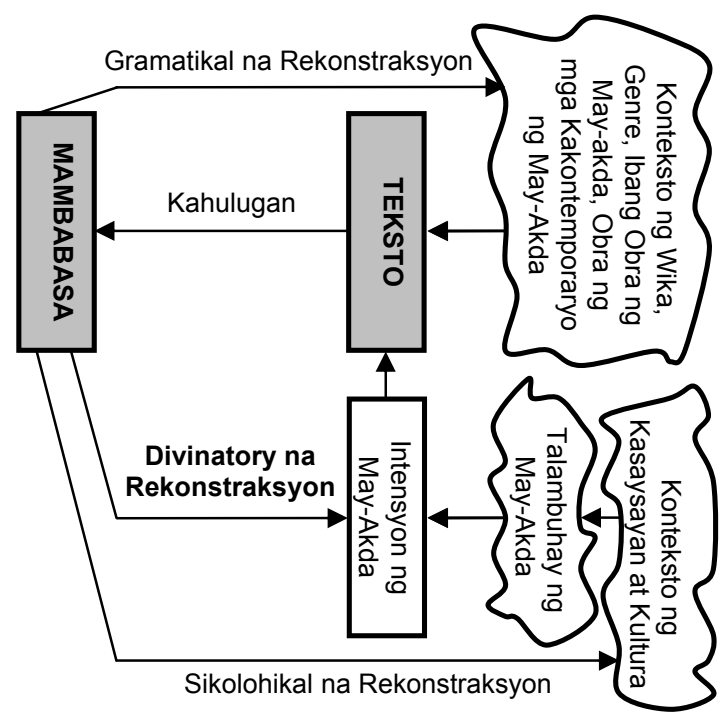

Pigura 4: Ang Divinatory na Rekonstraksyon

Sabay sa kanyang pagmungkahi na empatikong tumawid ang mambabasa patungo sa partikularidad ng itensyon ng may-akda, itinakwil ni Schleiermacher ang rasyonalismo ng Enlightenment at nagpatianod na lamang sa agos ng Romantisismo kung saan mas mahalaga ang intuwisyon, imahinasyon at damdamin. Kahit pa man na sa kanyang unang dalawang rekonstraksyon sinunod ni Schleiermacher ang landas ng rasyonalismo, sa bandang huli lumihis din siya para maisalba ang kanyang hermenyutika mula sa 
natuklasan niyang pundasyunal na mga suliranin. Ito ang dahilan kung bakit para sa kanya ang isang sining ang proseso ng interpretasyon, sa halip na isang siyensya. Sinabi ni Gadamer: "nakapaloob sa hermenyutika ang gramatikal at sikolohikal na interpretasyon. Ngunit ang partikular na kontribusyon ni Schleiermacher ay ang sikolohikal na interpretasyon. Sa kalaunan ito ay isang divinatory na proseso, isang paglalagay ng sarili sa buong balangkas ng may-akda, isang paglikha muli sa malikhaing paggawa." ${ }^{4}$ Sa kabuuan magkakasama dapat ang mga proseso ng gramatikal, sikolohikal at divinatory na rekonstraksyon para magiging mas malaki ang tsansang matutukoy nga ng mambabasa ang intensyonal na kahulugan ng may-akda.

Bukod sa kanyang iminungkahing mga proseso ng interpretasyon, may isa pang mahalagang kontribusyon si Schleiermacher sa pag-inog ng modernong hermenyutika, at ito ay ang kanyang prinsipyo na ang hermenyutika ay dapat isang unibersal na proseso. Ibig sabihin, ang hermenyutika na ginagamit para sa bibliya ay dapat maaari ring ipataw sa pananaliksik sa larangan ng panitikan, o hindi kaya sa batas, o hindi kaya sa kasaysayan. Taliwas ito sa kaugalian noong panahon ng Middle Ages at Renaissance kung kailan may kanyakanyang pamamaraan ang bawat larangan at disiplina kung papaano dapat isinasagawa ang proseso ng interpretasyon. Dahil dito pinaparangalan si Schleiermacher bilang ama ng modernong hermenyutika, at ang kanyang paggamit ng hermenyutika sa larangan ng teolohiya ay isa sa mga dahilan kung bakit pinaparangalan din siya bilang ama ng modernong Protestanteng teolohiya.

\section{Pagsasalin ayon kay Schleiermacher}

Kaakibat ng hermenyutika ni Schleiermacher ay ang kanyang teorya sa pagsasalin. Kagaya ng nabanggit na, isa siyang mahusay na tagapagsalin, at sa katunayan patuloy pa ring ginagamit hanggang ngayon sa Alemanya ang kanyang nagawang salin sa ilang mga dialogo ni Platon. Para sa kanya ang pagsasalin ay hindi lamang ang simpleng paglilipat ng isang teksto mula sa kanyang pinagmumulang wika patungo sa isang papupuntahang wika. Gamit ang kanyang hermenyutika batid ni Schleiermacher ang malaking problema ng pagsasalin dulot ng katotohanang ang isang teksto ay may kanyang sariling lingguwistika at sikolohikal na mga konteksto na nanganganib mawala, o masira, kapag ito ay ililipat sa naiibang lingguwistika at sikolohikal na mga konteksto ng patutunguhang wika ng mambabasa. Kapag nawawala at nasisira ang mga kontekstong ito, sigurado ding mawawala o masisira ang intensyunal na kahulugang nakapaloob sa isang teksto.

Ang pinakaunang problemang mararanasan ng tagasalin ay ang kawalan ng pagkakatugma-tugma ng maraming salita ng source at target na mga wika. Halimbawa, may salitang palis ang wikang Boholano na tumutukoy sa panahon ng araw matapos ang tanghali hanggang alas tres $\mathrm{o}$ alas kuatro ng hapon, at wala itong eksaktong katumbas sa wikang Filipino at Tagalog. Kaya

${ }^{4}$ Gadamer, Truth and Method, 187. 


\section{SCHLEIERMACHER AT DILTHEY}

kapag ito ay isinalin bilang tanghali, o di kaya bilang hapon, malinaw na masisira lamang ang kahulugan nito. At kapag pilit naman itong isalin bilang panahon sa pagitan $n g$ tanghali at hapon, masisira naman ang anyo nito, lalo na kapag ang pinaguusapan natin ay tula, o hindi kaya titik ng isang awitin. Ang problema ng kawalan ng pagkakatugma-tugma ng maraming salita ng source at target na mga wika ay kadalasan nagtutulak sa mga tagapagsalin na gumawa na lamang ng paraphrase o hindi kaya ng isang imitasyon, na sa pananaw ni Schleiermacher ay hindi tunay na pagsasalin.

Para kay Schleiermacher may dalawang opsyon lamang ang pagsasalin: "maaaring hayaan na lamang mamayapa ng tagasalin ang may-akda hanggang sa kaya niya at hatakin ang mambabasa patungo sa may-akda, o hayaan na lamang niyang mamayapa ang mambabasa hanggang sa kaya niya at hatakin ang mayakda patungo sa mambabasa." 5

Ang pinakakilalang tagapagtaguyod ng pangalawang opsyon ng pagsasalin ay walang iba kung hindi si Martin Luther (1483-1546), na kilala hindi lamang bilang isang dakilang Repormista, kung hindi pati na rin bilang isa sa mga kauna-unahang mga intelektwal na nakapagsalin sa bibliya mula sa wikang Latin patungo sa mga modernong wika ng Europa. ${ }^{6}$ Sa pananaw ni Luther para lubusang maintindihan ng target na mambabasa ang tekstong isasalin, ang pagsasalin ay dapat isang prosesong hahatak sa teksto mula sa kanyang orihinal na lingguwistika at sikolohikal na mga konteksto patungo sa lingguwistika at sikolohikal na mga konteksto ng target na mambabasa. Dahil Aleman ang target niya na wika, pinangalanan niya ang prosesong ito bilang Verdeutschung, o Alemanisasyon, o domestikasyon, kung saan mag-aanyong lokal at pamilyar ang banyagang teksto sa pananaw ng kanyang target na mambabasa.

Hindi maipagkailang naging epektibo ang estratihiya ni Luther, lalo na kapag susukatin ito gamit ang kanyang minimithing mapalapit ang bibliya sa buhay ng nakararaming Aleman, dahil talagang hinatak niya ang teksto nito papunta sa kanilang Alemang konteksto. Ngunit para kay Schleiermacher, na naniniwala na ang pinakasukatan ng kahulugan ay ang kahulugan na taglay sa isipan ng may-akda noong isinulat niya ang teksto, ang teorya sa pagsasalin ni Luther ay hindi katanggap-tanggap. Pabor si Schleiermacher sa unang opsyon na nabanggit niya, kaya iminungkahi niya na sa halip na hatakin ang teksto palayo sa kanyang pinagmumulang lingguwistika at sikolohikal na mga konteksto at papunta sa lingguwistika at sikolohikal na mga konteksto ng mga target na mambabasa, dapat ang mga target na mambabasa ang silang hahatakin papunta sa pinagmumulang mga konteksto ng isasaling teksto.

Ibig sabihin, kabaligtaran ang teorya ng pagsasalin ni Schleiermacher sa mas nauna, mas subok, at mas laganap na sistema ng pagsasalin na itinuturo ni

\footnotetext{
${ }^{5}$ Friedrich Schleiermacher, "On the Different Methods of Translating (Excerpts)," in Schulte, Rainer \& Biguenet, John, eds., Theories of Translation: An Anthology of Essays from Dryden to Derrida (Chicago: University of Chicago Press, 1992), 42.

6 Tingnan sa Michael Forster, "Friedrich Daniel Ernst Schleiermacher," in Stanford Encyclopedia of Philosophy.
} 
Luther. Kung ang pagsasalin para kay Luther ay dapat isang Verdeutschung, o Alemanisasyon, o domestikasyon, para kay Schleiermacher dapat isa itong pagsasabanyaga, kung saan ang banyagang teksto ay dapat mananatiling may anyong pagkabanyaga kahit pa man ito ay nailipat na sa target na wika. Kahit pa man mas mahirap basahin ang salin na isinasagawa sa ilalim ng teorya ni Schleiermacher, walang duda na mas malapit nga ang kahulugan nito sa orihinal na teksto kaysa salin na isinasagawa sa ilalim ng proseso na pinapaboran ni Luther. Para kay Schleiermacher ang layunin ng pagsasalin ay "maipahayag ang may-akda na nagsasalita sa isang paraang maiisip natin na ganoon nga siya magsasalita kapag alam lang niya ang ating wika." 7

Sa antas ng aktwal na pagsasalin ang ibig sabihin ng paghatak ng target na wika at target na mambabasa patungo sa lingguwistika at sikolohikal na mga konteksto ng isasaling teksto ay ang pagmamanipula sa mga problematikong salita ng target na wika para matugunan ang hindi pagkakatugma-tugma ng mga salita mula sa pinagmumulan at patutunguhang mga wika. Binanggit ni Michael Forster, sa kanyang sanaysay na "Friedrich Daniel Ernst Schleiermacher," bilang halimbawa ang Griyegong salitang arête ( $\alpha \varrho \varepsilon \tau \dot{\eta})$, na kadalasang isinasalin sa wikang Ingles bilang virtue. ${ }^{8}$ Pero ang arête at virtue ay hindi talaga lubusang tumutugma dahil arête din ang tawag sa kahusayan ng isang taong magsinungaling o magnakaw, na hinding-hindi tamang tawaging virtue sa Ingles. Pero para kay Schleiermacher maaaring gamitin ang salitang virtue bilang katumbas ng arête kapag malinaw sa mambabasa na sa konteksto ng isang pagsasalin ang virtue ay nagkakaroon ng panibago at espesyal na kahulugang na katumbas sa Griyegong arête. Madali itong gawin, hindi sa pamamagitan ng paraphrase, kung hindi sa pamamagitan ng maikling anotasyon. Sa ganitong paraan, papandayin muli ng tagasalin ang ilang malalapit na salitang nagmumula sa target na wika, para magkakaroon sila ng bagong kahulugan. Ito ang ginagawa, halimbawa, ng ilang mga Pilipinong intelektwal sa pagsasalin sa salitang "hegemony" na tinutumbasan nila ng Cebuanong salitang "gahum." Sa paglipas ng panahong paulit-ulit ginagamit nila ang salitang "gahum" bilang "hegemony," tila matagumpay nilang nabigyan ng bagong kahulugan ang naturang Cebuanong salita.

Katulad ng kanyang hermenyutika, may malinaw din na bakas ng Romantisismo ang teorya ng pagsasalin ni Schleiermacher. Bilang reaksyon sa paglalaganap ng iisang moderno, siyantipiko at rasyonal na kultura ng kanluran, nagpapahalaga ang kilusang ito sa pagkakaiba-iba ng mga pambansa, rehiyonal at pambayang mga kultura. Kaya kahit sa proseso ng pagsasalin matutunghayan natin ang kanyang malalim na respeto sa banyagang kultura.

Bukod pa sa pagpapanatili sa orihinal na kahulugan ang teksto, may isang mahalagang silbi rin ang proseso ng pagsasalin na iminungkahi ni Schleiermacher. Sinabi niya: "Kagaya ng ating lupa na posibleng napayaman at napataba, at ng ating klima na napaganda, matapos matamnan natin ng maraming banyagang halaman, gayundin ang palagay natin na ang ating wika...

\footnotetext{
${ }^{7}$ Schleiermacher, "On the Different Methods of Translating," 9.

8 Tingnan sa Forster, op cit.
} 
ay maaari lamang yumabong patungo sa tuktok ng kanyang kapangyarihan sa pamamagitan ng ibat-ibang pakikisalamuha nito sa banyaga. ${ }^{9}$ Habang ginagawa at lumalaganap ang pagsasalin ayon sa proseso ni Schleiermacher, yumayaman at yumayabong ang target na wika. Kung gagamitin natin ang konsepto ng ating lokal na teorisista sa wika na si Bonifacio Sibayan, isang mahalagang proseso ng intelektuwalisasyon ang pagsasalin ayon sa kaisipan ni Schleiermacher.

\section{Elaborasyon ni Dilthey}

Si Wilhelm Dilthey (1833-1911), isang Alemang pilosopo, ay ang intelektuwal na tagapagmana sa hermenyutika ni Schleiermacher at may-akda ng kanyang pinakakumprehensibong talambuhay. Pinayaman at pinayabong ni Dilthey ang hermenyutikang kanyang hiniram mula sa kanyang intelektuwal na ninuno.

Kung para kay Schleiermacher ang tekstong maaaring susuriin ng hermenyutika ay ang mga tekstong nakasulat at binibigkas lamang, para kay Dilthey ang teksto ay may mas malawak na sinasaklawan. Itinuturing niyang mga teksto ang kilos ng tao, ang kanyang sining, ang kanyang mga ritwal, ang istraktura ng kanyang pulitika at lipunan, at lahat ng bagay na nakapaloob sa isang kultura, na lahat maaaring suriin gamit ang hermenyutika.

Kilala si Dilthey bilang pantas na nagtatag sa pagkakaiba ng dalawang malalaking pangkat ng kaalaman: ang Naturwissenschaften, o ang mga natural at pisikal na mga siyensya, tulad ng biolohiya, kemika, pisika, heolohiya, at iba pa; at ang Geisteswissenschaften, o ang mga ispiritwal o pangtaong kaalaman, kung saan nakapaloob ang mga humanidades, tulad ng pilolohiya, pagaaral ng panitikan, sining at kultura, at teolohiya, at ang mga siyensyang panlipunan, tulad ng sosyolohiya, sikolohiya at ekonomiya.

Bilang isang Romantisista, tinutulan ni Dilthey ang rasyonalistang kaisipan na dapat sundin ng Geisteswissenschaften ang metodolohiya ng Naturwissenschaften. Sa kanyang pananaw magkakaiba ang dalawang kaalamang ito, at dapat lamang magkakaiba din ang kani-kanilang pamamaraan. Kung obserbasyon, eksperimentasyon, kwantipikasyon at kalkulasyon ang pamamaraan ng pananaliksik sa larangan ng natural at pisikal na mga siyensya, hermenyutika ang sagot ni Dilthey para sa pananaliksik sa larangan ng mga ispiritwal at pangtaong kaalaman. Binigyang diin niya: "pag-uunawa at Interpretasyon ang mga metodo na ginagamit sa lahat ng mga pangtaong agham."10 Kung para kay Schleiermacher ginagamit lamang ang hermenyutika sa teolohiya, pilosopiya, at sa pagaaral ng panitikan, kasaysayan at batas, para kay Dilthey ito ay mahalaga rin sa marami pang disiplinang nasasaklawan ng humanidades at agham panlipunan.

\footnotetext{
${ }^{9}$ Schleiermacher, "On the Different Methods of Translating," 53.

10 Wilhelm Dilthey, "The Understanding of Other Persons and the Life-Expressions,"
} in The Hermeneutics Reader, 152. 
Katulad kay Schleiermacher ang hermenyutikang inilahad ni Dilthey ay isa ring proseso ng kontekstuwalisasyon ng sinusuring teksto. Kung lingguwistika at sikolohikal na mga konteksto ang pinagtutuunang pansin ni Schleiermacher, gumagamit si Dilthey ng ibang kontekstong hinango niya mula sa pilosopiya ni G. W. F. Hegel (1770-1831): ang objectiver Geist, o kolektibong kamalayan. Sumasaklaw ang kolektibong kamalayang ito sa "estilo ng pamumuhay at anyo ng panlipunang pakikisalamuha pati na ang mga sistema ng layunin na binuo ng lipunan para sa kanyang sarili at mga kustombre, batas, estado, relihiyon, sining, siyensya at pilosopiya."11 Sa madaling salita, ito ang suma total ng mga inter-subhektibong produkto at likha ng tao sa isang kultura sa loob ng isang yugto ng panahon. At dito nagmumula ang lahat ng ekspresyon, teksto at galaw, dahil "kahit ang obra ng isang henyo ay nagpapahayag pa rin ng mga ideya, damdamin, at pagpapahalaga na taglay ng nakararami sa loob ng isang panahon at kapaligiran."12 Naniniwala siya na ang kolektibong kamalayan ay ang pinakaganap na konteksto na maaaring gamitin para matukoy ang kahulugan ng anumang ekspresyon, teksto o galaw. Para sa kanya ang rekonstraktibong interpretasyon ay isang rekonstraksyon ng isang espisipikong kolektibong kamalayan.

Kagaya sa nangyari kay Schleiermacher, napansin din ni Dilthey na kahit ang panikaganap at pinakamasinop na rekonstraksyon ng kolektibong kamalayan ay hindi makapagbibigay ng kasiguraduhan na lubusan ngang matutukoy ng proseso ng interpretasyon ang kahulugan ng isang ekspresyon, teksto o galaw, dahil ang kolektibong kamalayan ay maaari lamang magturo sa mambabasa kung ano ang mga kahulugang laganap at komon sa loob ng isang yugto ng lipunan, at madalas hindi nito kayang ituro sa mambabasa ang personal at indibidwal na mga aspeto ng kahulugang maaaring taglay lamang ng may-akda. Kaya kailangan din ni Dilthey ang divinatory na rekonstraksyon ni Schleiermacher. Ngunit kahit pa man Romantisista din si Dilthey hindi niya basta-basta sinunod ang medyo malabo at may pagkamistikal na prosesong ito. Ang pinaka kontribusyon niya sa hermenyutika ni Schleiermacher ay ang kanyang rasyonal na paliwanag at elaborasyon sa problematikong pamamaraang divinatory na rekonstraksyon.

Ginawa ito ni Dilthey sa pamamagitan ng isa pang konsepto, ang Erlebnis, na para sa kanya ay isang karanasang tumitibok ng buhay, tulad ng pag-ibig, galit, pagka-api, rebolusyon, kagandahan, hinagpis, ambisyon, kabiguan, at pagiging magkaibigan. Binigyang diin ni Dilthey na maintindihan ang Erlebnis ng lahat ng tao sa lahat ng panahon, batay sa katotohanang ang lahat ng tao sa lahat ng pahanon ay nakakaranas nito sa alin mang yugto ng kani-kanilang buhay. Sinulat niya: "Ang kaluluwa ay tumatahak sa mga pamilyar na landas kung saan siya ay nasiyahan, nagdurusa, nagmimithi at kumilos sa kaparehong mga sitwasyon."13 Kaya sa halip na sundan ang hindi malinaw na proseso ng pagtawid ni Schleiermacher patungo sa sikolohiya ng

\footnotetext{
11 Ibid., 155.

12 Ibid., 155.

13 Ibid., 159 .
} 
may-akda, ginamit ni Dilthey ang Erlebnis bilang mga baitang papunta sa isang mas rasyonal na pagpasok sa sikolohiya ng teksto. Naniniwala si Dilthey na matatamo ang pinakaganap na pag-uunawa tuwing empatikong naisasabuhay ng mambabasa ang mga karanasang buhay, o Erlebnis na nakapaloob sa teksto.

\section{Mga Mahahalagang Puntos ng Romantisismong Hermenyutika para sa Araling Lokal na Pag-aaral ng Teksto at Kultura}

May iilang mahalagang puntos ang makukuha natin mula sa hermenyutika nina Schleiermacher at Dilthey na maaaring magamit natin sa pagpapayaman at pagpapayabong sa sarili nating tekstuwal at kultural na mga proyekto, lalong-lalo na sa larangan ng araling Pilipino.

Unang-una sa mga ito ay ang kahalagahan para sa ating mga lokal na iskolar at intelektwal na maging bihasa sa orihinal na wika na ginagamit ng sunusuring teksto. Ang akala nating simpleng lingguwistikong pamantayan nina Schleiermacher at Dilthey ay lalabas pala na napakabigat na kahilingan para sa isang mambabasa sa larangan ng araling Pilipino. Ito ay dahil ang ating mga historikal na dokumento ay kadalasang nakasulat sa wikang Espanyol, Ingles at Hapones. Pati ang wikang Tagalog na minsan ginagamit ng ilang historikal na dokumento ay ibang-iba sa kasalukuyan nating Tagalog o Filipino. Nandiyan rin ang dagdag na hinihiling kapag ang sinusuring teksto ay nanggagaling sa alin man sa ating napakaraming pangkat etniko. Wala tayong problema sa mga tekstong nakasulat sa Ingles at Filipino, pero pagdating sa mga tekstong nasa Espanyol, Hapones, at sa anumang rehiyunal na wika natin, doon tayo magkakaproblema dahil kulang na kulang ang ating kasanayan sa mga ito. Ang hermenyutika nina Schleiermacher at Dilthey ay nagtuturo sa ating mga lokal na iskolar at intelektwal na bigyan ng sapat na pansin ang pagsasanay sa mga wikang hihilingin ng kani-kanilang mga tekstuwal na proyekto.

Pangalawa sa mga ito ay ang kahalagahan para sa ating mga iskolar at intelektuwal na magkakaroon ng sapat na kabatiran sa kultural at historikal na mga konteksto ng anumang paksang susuriin nila. Tayong mga Pilipino ay madalas napupulaan dahil sa kahinaan ng ating kamalayan tungkol sa sarili nating kultura at kasaysayan. Totoo man o hindi ang pulang ito, kapag susundin natin ang hermenyutika nina Schleiermacher at Dilthey, ang bawat paksang susuriin natin ay magiging isang pagkakataong mapapalakas natin ang ating kamalayan tungkol sa mga espisipikong aspeto ng ating kultura at kasaysayan, mapasentral man o maparehiyunal ang mga ito.

Pangatlo sa mga ito ay ang implikasyon na dahil ang ating mga sariling iskolar at intelektuwal ay mas malapit sa mga lingguwistika at sikolohikal na mga konteksto ng alin man sa ating mga lokal na teksto, kung hindi man sila nakapaloob mismo sa mga kontekstong ito, sila dapat ang mangunguna sa pagaaral at pagsusuri sa mga tekstong ito, at hindi dapat ang mga banyagang iskolar at intelektuwal. Kapag susundin natin ang hermenyutika nina Schleiermacher at Dilthey lalabas na mas madali ang proseso ng interpretasyon, at mas malaki 
ang tsansang matukoy ang intensyonal na kahulugan, para sa ating mga sariling iskolar at intelektuwal kaysa sinumang banyagang iskolar at intelektuwal.

Pang-apat sa mga ito ay ang implikasyon na ang pag-aaral at pagsusuri ng teksto ay isang bagay na nagiging mas mahusay sa paglipas ng pahanong ginugugol ng isang iskolar o intelektuwal sa tuloy-tuloy na pag-aaral at pagsusuri ng mga teksto. Ito ay dahil habang ibinababad nila ang kanilang kaalaman sa pag-uunawa ng mga kultural at historikal na konteksto, lumalawak at lumalalim ang kani-kanilang kaalaman na magpapadaili, magpapabilis at magpapahusay sa mga sumusunod nilang mga tekstuwal na proyekto. Ang isang iskolar at intelektuwal ay hindi maaaring iskolar at intelektuwal lamang sa taong ito, at sa susunod na taon ay hindi muna, para lamang bumalik ulit sa paglipas ng dalawa o tatlong taon. Para kina Schleiermacher at Dilthey ang proseso ng interpretasyon ay isang seryosong bokasyon para sa mga seryosong iskolar at intelektuwal.

Panglima sa mga ito ay mula sa teorya ng pagsasalin ni Schleiermacher na pawang sumasalungat sa teorya ng pagsasalin na dominante ngayon sa ating bansa. Sa kasalukuyan ang ating pagsasalin ay kumikiling sa paghahatak ng teksto papunta sa konteksto ng target na mambabasa. Kung tutuusin natin ang prosesong ito ay kapareho sa Alemanisasyon, o domestikasyon, ni Luther, na siya namang tinutulan ni Schleiermacher. Maaaring labis na labis na ang ating ugnayan sa banyagang kultura, lalong-lalo na iyong mga nanggagaling sa kanluran, pero kadalasan sa mga ugnayang ito naisasantabi natin ang ating wika. Siguro panahon na upang payamanin at payabungin natin ang ating wika sa pamamagitan ng paghamon sa mga Pilipinong mambabasa na makisalamuha sa salin na may banyagang anyo, kagaya ng iminungkahi ni Schleiermacher para sa wikang Aleman.

Pang-anim sa mga ito ay mula sa pagpalawak ni Dilthey sa saklaw ng hermenyutika na nag-aanyaya sa atin na gamitin ito sa pag-aaral ng anumang teksto, o mala tekstong bagay, tulad ng kilos ng tao, sining, ritwal, istraktura ng pulitika at lipunan, at alin mang bagay na nakapaloob sa isang kultura. Dagdag pa dito ay ang kanyang kaugnay na anyaya na gamitin ang hermenyutika hindi lamang sa teolohiya, pilosopiya, pilolohiya, at sa pag-aaral ng panitikan at batas, kung hindi pati na rin sa ibang disiplina at larangang na kasali sa malalaking pangkat ng kaalaman ng humanidades at agham panlipunan, o ang tinatawag niyang Geisteswissenschaften.

Department of Filipino, De La Salle University-Manila, Philippines

\section{References}

Dilthey, Wilhelm, “Awareness, Reality: Time,” in Mueller-Vollmer, Kurt, ed., The Hermenentics Reader (New York: Continuum Publishing Company, 1997), 149-152.

, "The Understanding of Other Persons and the LifeExpressions," in Mueller-Vollmer, Kurt, ed., The Hermeneutics Reader (New York: Continuum Publishing Company, 1997), 149-152. 


\section{SCHLEIERMACHER AT DILTHEY}

Forster, Michael, "Friedrich Daniel Ernst Schleiermacher," in Stanford Encyclopedia of Philosophy, http://plato.stanford.edu/entries/ schleiermacher/ (April 2002).

Gadamer, Hans-Georg, Truth and Method (New York: Continuum Publishing Company, 1999).

Makkreel, Rudolf, "Wilhelm Dilthey," in Stanford Encyclopedia of Philosophy, http://plato.stanford.edu/entries/dilthey/ (January 2008).

Margolis, Joseph, "Schleiermacher among the Theorists of Language and Interpretation," in The Journal of Aesthetics and Art Criticism, 45:4 (Summer, 1987), 361-368.

Niebuhr, Richard, "Schleiermacher On Language and Feeling," in Theology Today, 17:2 (July 1960), 150-167, http://theologytoday.ptsem.edu/ jul1960/v17-2-article2.htm.

Quito, Emerita, Philosophers of Hermeneutics (Manila: De La Salle University Press, 1990).

Ramberg, Bjorn \& Gjesdal, Kristin, "Hermeneutics," in Stanford Encyclopedia of Philosophy, $\quad$ http://plato.stanford.edu/entries/hermeneutics/ (November 2005).

Schleiermacher, Friedrich, "General Hermeneutics," in Mueller-Vollmer, Kurt, ed., The Hermeneutics Reader (New York: Continuum Publishing Company, 1997), 72-86.

"Grammatical and Technical Interpretation," in MuellerVollmer, Kurt, ed., The Hermeneutics Reader (New York: Continuum Publishing Company, 1997), 86-97.

"On the Different Methods of Translating (Excerpts)," in Schulte, Rainer \& Biguenet, John, eds., Theories of Translation: An Anthology of Essays from Dryden to Derrida (Chicago: University of Chicago Press, 1992), 36-54.

Sherratt, Yvonne, Continental Philosophy of Social Science: Hermeneutics, Genealogy and Critical Theory from Greece to the Twenty-First Century (Cambridge: Cambridge University Press, 2006).

Tapper, Bonno, "Dilthey's Methodology of the Geisteswissenschaften," in The Philosophical Review, 34:4 (July 1925), 333-349.

Venuti, Lawrence, "Genealogies of Translation: Schleiermacher," in Erudit, http://id.erudit.org/iderudit/037096ar (1991). 